Saudi Journal of Oral and Dental Research

Abbreviated Key Title: Saudi J Oral Dent Res

ISSN 2518-1300 (Print) |ISSN 2518-1297 (Online)

Scholars Middle East Publishers, Dubai, United Arab Emirates

Journal homepage: https://saudijournals.com/sjodr

Review Article

\title{
Snap on Smile: A Systematic Review
}

Dr. Laila Mohammed Alanazi*, Dr. Abdulrahman Abdullah Alkhashrami, Dr. Rayan Abdullah Albader, Dr. Shahad Ali Alasiri, Dr. Ahmed Fahad Althumairy, Dr. Waad Mohammed Alghamdi, Dr. Nabeel Mohammed Munshi, Dr. Fatima Sultana

King Abdulaziz University Saudi Arabia

DOI: $\underline{10.36348 / \text { sjodr.2020.v05i11.001 }}$

| Received: 12.10 .2020 | Accepted: 28.10.2020 | Published: 06.11.2020

*Corresponding author: Dr. Laila Mohammed Alanazi

\section{Abstract}

An unimaginable change has occurred in the past 50 years in the restorative dentistry. People are nowadays more concerned about their smile and hence opting for various dental procedures to get that perfect smile. According to the World Health Organization, oral health is often inter-twisted with the general health that determines the quality of life of a person and a good oral health reduces mortality. It is important to balance between the knowledge of the dental professionals about the smile aesthetics and the perception of the patient to create a dazzling and pleasing smile. The aesthetic dentistry treatment planning May includes interacting of different dental disciplines like endodontics, orthodontics, periodontics prosthodontics, and restorative modalities. The snap on smile is a removable, flexible and adjustable device that needs no preparation or reconstruction of the tooth structure. It doesn't require any anaesthetic injections. In fact it is non-invasive that makes it perfectly reversible. The purpose of this systematic review is to review the literature about the snap on smile. Data was extracted from the online databases like Med-line and Pub-Med Central, and tabulated using the pre designed data extraction forms. 11 articles were included in the study of the systematic review of literature about the snap on smile. The individuals with aesthetic smile appear more attractive in the photograph than the individual with no aesthetic smile. Snap on Smile can create a person's image and also inspire his self-confidence. Snap on Smile offers an immediate change in the smile and gives the most compelling experience by the patient. The snap on smile is a total non-invasive and reversible treatment that gives an instant change and adds up to the attractiveness of an individual's face. The snap on smile is a total non-invasive and reversible treatment that gives an instant change and ads up to the attractive of an individual's face. The Snap on Smile gives a temporary instant results of a dazzling smile and may last from 2 to 5 years, it requires no adhesives, no cementation, no bonding, no invasion, no impingement, and is inexpensive when compared with Veneer and Dental Implants. However it has few drawbacks like it is less durable, gives more fake look, and gives bulky appearance, with increased risk of decay and development of plaque.

Keywords: Snap on smile, aesthetic smile, snaps on veneer, aesthetic dentistry, and smile makeover.

Copyright $\odot \mathbf{2 0 2 0}$ The Author(s): This is an open-access article distributed under the terms of the Creative Commons Attribution 4.0 International License (CC BY-NC 4.0) which permits unrestricted use, distribution, and reproduction in any medium for non-commercial use provided the original author and source are credited.

\section{INTRODUCTION}

With a beautiful smile, one can convey to be pleasant, attractive, likeable and confident. As believed that people who are attractive are more likely to get good jobs, life partners, experience a happy and fulfilling life [1]. Such societal expectations start from childhood and lasts a lifetime. A perfect dazzling smile could enhance the self-esteem of a person and helps to affect people personally and professionally [2]. With the help of social media, television and fashion magazine, many of the people are aware of the aesthetic smile or aesthetic dentistry.
The present young generation give more significance to the overall appearance and the key role of a beautiful smile is undeniable [3]. The aesthetic dentistry treatment planning may include a wide variety of dental disciplines like endodontics, orthodontics, periodontics prosthodontics, and restorative modalities [4]. Females are more cautious about their physical appearance when compared to males, especially regarding their dental appearance [5].

According to the World Health Organization, oral health is often inter-twisted with the general health that determines the quality of life of a person and a good oral health reduces mortality. Increasing the overall health of the patient by managing the oral health 
is the moral of dentistry [6]. The teeth framed by lips, contoured by gingiva and number of spaces and gaps define the smile aesthetics. The harmony and symmetry of the aesthetic smile is determined by the gingival exposure at smiling, arc of smile, teeth proportions, mid-line shift, axial inclination change, buccalcorridors, gingival contours and height, Diastema, and teeth colour [7].

People are nowadays more concerned about their smile and hence opting for various dental procedures to get that perfect smile. It is important to balance between the knowledge of the dental professionals about the smile aesthetics and the perception of the patient to create a dazzling and pleasing smile [8]. The smile plays a significant role in social interaction and enhances a person's attractiveness [9].

An unimaginable change has occurred in the past 50 years in the restorative dentistry. The acrylic resins have been replaced by silver amalgam which is now replaced by composite resin in the present times [10]. Basically the smile is affected by 3 main factors like: teeth, lip framework and gingival scaffold. The teeth in the oral cavity should fit in the rule of 'Golden Proportion' [11].

\section{Rationale behind this study}

The main purpose of this systematic review is to review the literature about the snap on smile, its application and provide the guidelines to be carried out by the dentist as well as the patients to avoid the complications.

\section{AIM \& OBJECTIVES}

The main aim of this study is to assess prior studies and review all the literature related to Snap on smile. This can be attained by:

- Conducting a systematic review of studies about snap on smile.

- Identifying various applications of Snap on Smile over Veneer/ Dental Implants.

- Identifying the price range of Snap on Smile over Veneer/Dental Implants.

- Determining the durability of snap on smile and comparing with Veneer/ Dental Implants.

\section{Snap on smile}

The snap on smile is a removable splint of only 10 or 13 units to cover the lingual and facial surfaces of the teeth with the occlusal surface of molar cuts [12]. The unique design allows the patient to snap the splint into the oral cavity and is able to eat and chew with the snap on smile. Snap on smile is made up of crystallized acetyl resin; it keeps the appliance to be thin as $0.5 \mathrm{~mm}$ with no compromise in strength. It is dense, glossy, strong and stiff. Crystallized acetyl resin is the toughest and highly fatigue resistant commercial thermoplastics. This material is non-toxic and is also used in the replacements of heart valves and other minor dental appliances.

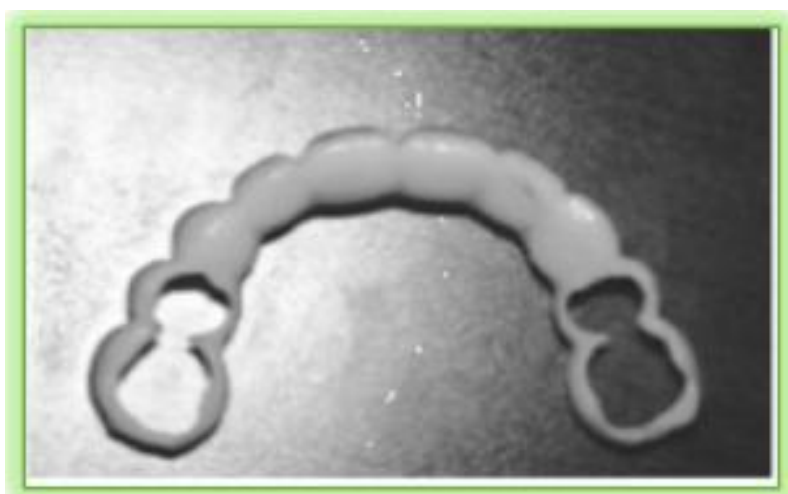

Occlusal surface of Snap on Smile [12]

The snap on smile is the flexible and adjustable device that needs no preparation or reconstruction of the tooth structure; it doesn't require any anaesthetic injections or cementation procedures. In fact it is non-invasive that makes it perfectly reversible [13].

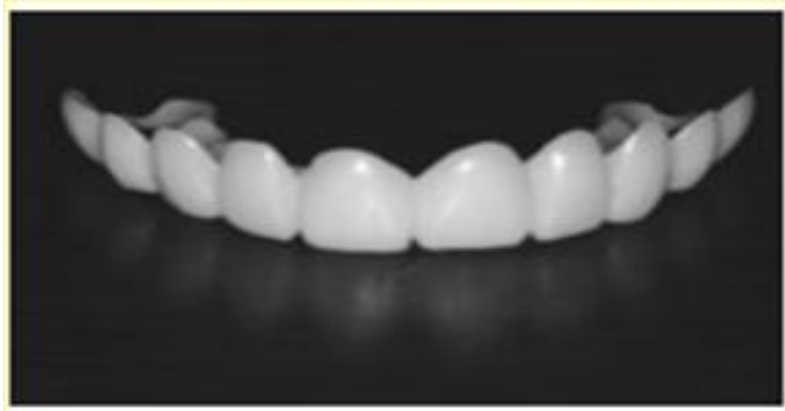

Facial surface of Snap on Smile [12]

\section{Advantages of snap on smile}

The Snap on smile has several advantages over the other aesthetic smiles like

- It needs no teeth preparation for application,

- It needs no cementation on the original teeth,

- It needs no anaesthesia injections,

- It needs no invasion,

- It needs no impingement on the surface of the original teeth.

\section{Snap on smile indications}

- Opening \& Restoring Vertical Dimension

- Removable Partial Denture (Missing Teeth)

- Implant Provisional and Attachment

- Aesthetic / Cosmetic Smile Enhancement (Alignment, Whitening, Severe Crowding)

\section{Process to do snap on smile}

Impression: A good impression shows accurate margins and height of the existing teeth, technique is significant in case of Snap on Smile [14]. 
Bite registration: A customized type of bite registration is used for accuracy as snap on smile it is done digitally.

Shade and shape: The accurate and desired colour and shape of the teeth that fits in the patient's oral cavity is selected by the patient and the dentist. The snap on smile is available in monochromatic shades and the perfect one for the patient can be selected.

Photographs: In most of the cosmetic dentistry devices photography is highly recommended.

\section{Insertion guidelines for snap on smile}

Placement in the mouth: The snap on smile is aligned on the teeth or edentulous cavity. The two hands are used to apply the snap on smile and pressed until the resting position is attained. It should impinge the tissue of the gingiva but will meet the gingiva. If more tightness is felt by the patient then it should be removed and reapplied after sometime until it becomes more comfortable as it has elastic nature and adjusts in the oral cavity. No sharp or uncomfortable edges should be felt by the patient like any other dental appliances. After acclimation the patient should undergo the phonetic exercises to check its effect on speaking. The patient should be guided to insert and remove the snap on smile with two hands in-order to avoid pressure or strain on the device [15].

Removal from the oral cavity: The patient should initiate the process of removal of snap on smile at the places with higher resistance by loosening it and moving it from side to side to free the device. The four lateral movements (side by side movement from posterior to anterior) need to be used while removing the snap on smile. The patient should not remove snap on smile using just one or two movements [15].

\section{Guidelines for using}

- Always remove appliance using two hands.

- Use a Snap on Smile anti-bacterial gel to prevent bad breath and decay of teeth

- Brush the inner part of the appliance two times a day using a soft brush

- Use plain water instead of tooth paste as it could dull the appliance.
- Snap on smile cleaning powders available in the markets can be used to remove stains from the appliance.

- When not in use, store the appliance in the carrying case to protect it.

\section{METHODOLOGY \\ Search Design}

The systematic search was done using various databases like Med-line, Pub-Med Central, Embase, Scopus in the English language with the aim to review the literature related to Snap on Smile. Data was extracted from the online databases and tabulated using the pre designed data extraction forms. The predesigned data extraction form included the information about the study citation and characteristics (name of the Author/s, year of publication, country of study, data source and study content of snap on smile). Extracted data from Med-line and Pub-Med Central is to be entered in the pre designed data extraction form created by Principal Investigator. The outcome is observed and the results are recorded. Each article selected for the study is closely reviewed and the data entered in the pre-designed tables are evaluated and handled by the principal investigator.

\section{Search Terms Used}

The search terms selected were in English language and were applicable to snap on smile. Search terms included are 'snap on smile', 'snap in denture' or 'snap on veneer', 'snap on smile outcomes', 'snap on smile complications', 'Hollywood smile', 'fake smile', 'aesthetic smile'. All these Mesh terms were for snap on smile and the risks/complications using the Boolean operator 'AND'.

\section{Inclusion and Exclusion Criteria}

The original list of articles or cases was screened to make them eligible for the study. The inclusion criteria of this study include all the articles or case reports, with snap on smile with both the genders (males and females). The exclusion criteria of the study are all the articles or cases not in the English language; treated the non-human subjects other than snap on smile studies. 


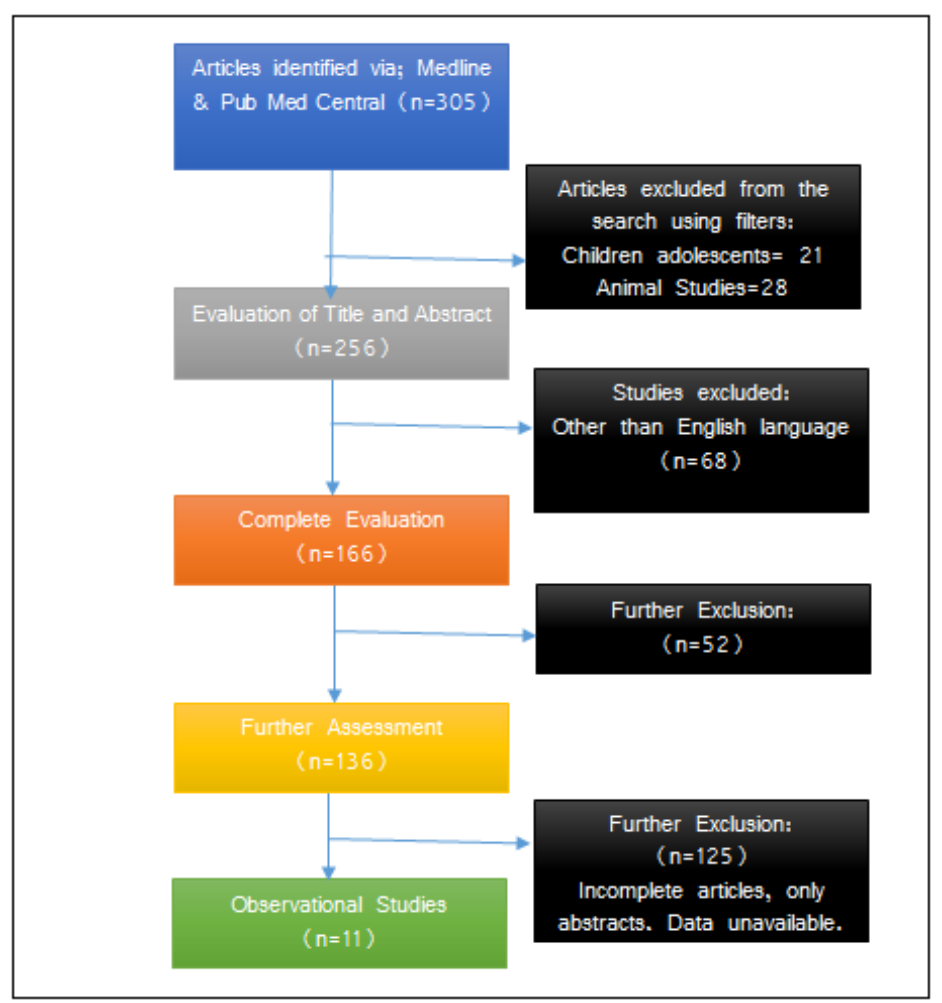

Flow Chart Showing the systematic review after applying the inclusion and exclusion criteria

\section{Number of articles to be reviewed}

The total articles to be reviewed for the total research may be more than 305 articles for this study. This research found that about total 305 articles related to our search terms. By applying the filters and limiting the articles with human studies, adult studies and English language studies, about 256 were sorted to study. The abstracts and titles were studied and by applying the inclusion and exclusion criteria, about 68 articles were selected and from this upon further assessment 125 articles were removed that had incomplete information, only abstracts and unavailability of the data and only 11 articles were included in the study of the systematic review of literature about the snap on smile.

\begin{tabular}{|c|c|c|c|c|}
\hline AUTHOR & $\begin{array}{l}\text { PERIOD OF } \\
\text { DATA } \\
\text { OLLECTION }\end{array}$ & $\begin{array}{l}\text { COUNTRY } \\
\text { OF STUDY }\end{array}$ & DATA SOURCE & STUDY CONTENT \\
\hline MG Messing et al. & 1995 & New Jersey & Dent Today & Smile architecture, beyond snap on smile \\
\hline JK Dong et al. & 1999 & Augusta & $\begin{array}{l}\text { International } \\
\text { Journal of } \\
\text { Prosthodont }\end{array}$ & $\begin{array}{l}\text { The aesthetics of smile, a review of the } \\
\text { studies }\end{array}$ \\
\hline Lorin Berland et al. & 2003 & Texas & Dent Today & $\begin{array}{l}\text { The aesthetic edge, a new approach to snap } \\
\text { on smile design }\end{array}$ \\
\hline $\begin{array}{l}\text { Daltro Eneas Ritt et } \\
\text { al. al. }\end{array}$ & 2006 & Brazil & $\begin{array}{l}\text { World Journal of } \\
\text { Orthodontics }\end{array}$ & Analysis of Smile photograph \\
\hline Mark Liechtung et al. & 2006 & New York & Dent Today & Snap on Smile, two case studies \\
\hline Malcmacher L et al. & 2006 & Cleveland & Dent Today & Snap on Smile: clinical applications \\
\hline Marc Liechtung et al. & 2010 & New York & Dent Today & $\begin{array}{l}\text { The snap on smile quadrant appliance; a new } \\
\text { treatment option for implant temporaries }\end{array}$ \\
\hline $\begin{array}{l}\text { Lawrence B } \\
\text { Blackmon et al. }\end{array}$ & 2010 & Los Angeles & Dent Today & $\begin{array}{l}\text { Snap on smile; a new smile, happy patient, } \\
\text { and further clinical applications }\end{array}$ \\
\hline Den Mat et al. & 2013 & USA & $\begin{array}{l}\text { Compend Contin } \\
\text { Edu Dent }\end{array}$ & $\begin{array}{l}\text { Den Mat's Snap on SMile offers conenient } \\
\text { solution for geriatric patients }\end{array}$ \\
\hline Lee Wilson et al. & 2015 & Mississippi & $\begin{array}{l}\text { JJ Tenn Dent } \\
\text { Assoc. Spring } \\
\text { SUmmer }\end{array}$ & $\begin{array}{l}\text { Amelogenesis imperfecta, Facial aesthetics } \\
\text { and snap on smile }\end{array}$ \\
\hline $\begin{array}{l}\text { Jonathan Es Quivel et } \\
\text { al. }\end{array}$ & 2020 & Managua & $\begin{array}{l}\text { J Esthet Restor } \\
\text { Dent }\end{array}$ & $\begin{array}{l}\text { The utilization of snap on provisionals for } \\
\text { dental veneer; form an analogy to a digital } \\
\text { approach. }\end{array}$ \\
\hline
\end{tabular}


The systematic review of literature related to snap on smile from the 11 selected articles showed study from a period of 1995 to 2020 . In Most of the studies the mean age of the patient was around 33 years. All the studies included males and females.

\section{DISCUSSION}

Snap on Smile can create a person's image and also inspire his self-confidence. In the present times, the people are more concerned about their looks and appearances [17]. For a dazzling, beautiful and youthful smile the patients depend on their dentist. In recent age, a paradigm shift has been seen in the field of dentistry [18]. The patient is ready to undergo surgery or anything that takes to get an aesthetic pleasant smile [19]. The patient seems to be satisfied seeing the change when they look in the mirror, that creates a renowned confidence in them.

There occur a strong association between smile and the facial attractiveness. The individuals with aesthetic smile appear more attractive in the photograph than the individual with no aesthetic smile [20]. The Snap on Smile depends on the face shape, placement pattern, buccal corridors, tooth shape, tooth size, tooth position and tooth colour. The influence is made on the smile by the presence or absence of buccal corridors [20]. Ritter et al. [21] Reported in his study that the aesthetic smile is not effected in the photograph by the negative spaces. Tjan et al. [22] in his study classified smile as high smile, average smile and low smile depending on the gingival display. Grosofsky et al. [23] reported in his study that white teeth didn't positively affect the attractiveness. Beall et al. [24] whereas reported that smile had an impact on the attractiveness of individuals.

With the present study we reviewed that, Snap on smile is completely tooth borne and fits over the teeth. With Snap on smile, patient can eat or speak without the dis-engagement of the appliance. Snap on smile doesn't cover the plate and also it doesn't impinge on the gingiva. The Snap on Smile is economical and can be an easy option for people who have an imperfect smile because of the missing tooth. It's a functional appliance in case of patients with para-functional habits.

In a survey it was found that $50 \%$ of the participants thought that the discolouration of the teeth influenced the smile [25]. Another study showed that a white and bright smile had a positive impact on the smile of a person [26, 27]. The review of literature showed that Snap on Smile can completely hide the discoloured teeth and also helps to create a white, bright and dazzling beautiful smile. The Snap on Smile requires no drilling for application unlike veneer and Dental Implants, It needs no adhesives for bonding unlike veneer, It requires no cementation on the original teeth unlike veneer, It needs no anaesthesia injections unlike Dental Implants application, It needs no invasion unlike veneer and Dental Implants, It requires no impingement on the surface of the original teeth like veneer. The Snap on Smile gives instant results when compared with Veneer and Dental Implants. It is comparatively inexpensive when compared with Veneer and Dental Implants.

The Durability of Snap on Smile is less when compared with Veneer and Dental Implants; that is about 2 to 5 years only. The Snap on Smile may not look like the natural teeth as there may be missing gaps between the teeth, the Veneer and Dental Implants looks more natural when compared with the Snap on Smile. Snap on Smile can give a fake smile, easily predictable by anyone. Unlike Veneer and Dental Implants; Snap on Smile directly fits over the natural teeth and hence may appear bulky. There is an increased risk of decay and development of plaque when compared with Veneer and Dental Implants.

\section{CONCLUSION}

In the Smile make-overs there are lot of challenges. Snap on Smile offers an immediate change in the smile and is the most compelling experience by the patient. Snap on smile is the most economical aesthetic dental make-over to give a dazzling smile and also hide the missing teeth. The snap on smile is a total non-invasive and reversible treatment that gives an instant change and ads up to the attractive of an individual's face. The Snap on Smile gives a temporary instant results of a dazzling smile and may last from 2 to 5 years, it requires no adhesives, no cementation, no bonding, no invasion, no impingement, and is inexpensive when compared with Veneer and Dental Implants. However it has few drawbacks like it is less durable, gives more fake look, and gives bulky appearance, with increased risk of decay and development of plaque. A lot of literature is not available about the snap on smile especially in Saudi Arabia in detail and further needs more research to be done in this topic.

\section{ETHICAL CONSIDERATIONS Compliance with ethical standards}

Ethical approval: This proposal does not contain any studies with human participants performed by any of the authors.

Conflict of interest: The authors do not have any commercial associations that might pose or create a conflict of interest with information presented in this communication. No intramural or extramural funding supported any aspect of this work

\section{REFERENCES}

1. Rodrigues, C. D., Magnani, R., Machado, M. S., \& Oliveira, O. B. (2009). The perception of smile attractiveness. The Angle Orthodontist, 79(4), 634. 
2. Coldstein, R.E. (1969). Study of the need for esthetics in dentisay. J Prosthet Dent. 21589-597

3. Golub-Evans, J. (1994). Unity and variety: essential ingredients of a smile design. Current opinion in cosmetic dentistry, 1.

4. Morley, J. (1999). Advanced smile design. Course presented at: Postgraduate Advanced Restorative Esthetics Program, Baylor College of Dentistry, Department of Continuing Education; Feb. 12, Dallas.

5. Dion, K., Berscheid, E., \& Walster, E. (1972). What is beautiful is good. Journal of personality and social psychology, 24(3), 285.

6. Bull, R., \& Rumsey, N. (2012). The social psychology of facial appearance. Springer Science \& Business Media.

7. Schabel, B. J., Franchi, L., Baccetti, T., \& McNamara Jr, J. A. (2009). Subjective vs objective evaluations of smile esthetics. American journal of orthodontics and dentofacial orthopedics, 135(4), S72-S79.

8. Behrend, D. A., Harcourt, J. K., \& Adams, G. G. (2011). Choosing the esthetic angle of the face: experiments with laypersons and prosthodontists. The Journal of prosthetic dentistry, 106(2), 102-108.

9. Malcmacher, L. (2006). Snap-on smile: clinical applications. Dentistry today, 25(9), 118-120.

10. Wilson, L., Bradshaw, J. P., \& Marks, M. K. (2015). Amelogenesis Imperfecta, Facial Esthetics and Snap-On Smile. The Journal of the Tennessee Dental Association, 95(1), 18-21.

11. Liechtung, M. (2006). Snap-on smile: two case studies. Dentistry today, 25(4), 42-42.

12. Esquivel, J., Villarroel, M., Tran, D., Kee, E., \& Bruggers, K. (2020). The utilization of snap- on provisionals for dental veneers: From an analog to a digital approach. Journal of Esthetic and Restorative Dentistry, 32(2), 161-170.

13. DenMat's. (2013). Snap-on Smile offers convenient solution for geriatric patients. Compend Contin Educ Dent; 34(2):152.

14. Blackmon, L. B. (2010). Snap-On Smile: a new smile, a happy patient, and further clinical applications. Dentistry today, 29(8), 38-38.

15. Messing, M. G. (1995). Smile architecture: beyond smile design. Dentistry Today, 14(5), 7476.

16. Dong, J. K. (1999). Jin. TH, Cho HW, Oh SC The esthetics of the smile: a review of some recent studies. Intern. Journal of Prosthodontics, 12(1), 9-19.

17. Ritter, D. E., Gandini Jr, L. G., Pinto, A. D. S., Ravelli, D. B., \& Locks, A. (2006). Analysis of the smile photograph. World journal of orthodontics, 7(3).

18. Berland, L., Traub, D., \& Williams, A. (2003). The aesthetic edge. A new approach to smile design. Dentistry today, 22(2), 70-73.

19. Pithon, M. M., Santos, A. M., de Andrade, A. C. D. V., Santos, E. M., Couto, F. S., \& da Silva Coqueiro, R. (2013). Perception of the esthetic impact of gingival smile on laypersons, dental professionals, and dental students. Oral surgery, oral medicine, oral pathology and oral radiology, 115(4), 448-454.

20. Richards, M. R., Fields Jr, H. W., Beck, F. M., Firestone, A. R., Walther, D. B., Rosenstiel, S., \& Sacksteder, J. M. (2015). Contribution of malocclusion and female facial attractiveness to smile esthetics evaluated by eye tracking. American Journal of Orthodontics and Dentofacial Orthopedics, 147(4), 472-482.

21. Ritter, D. E., Gandini Jr, L. G., Pinto, A. S., \& Locks, A. (2006). Esthetic influence of negative space in the buccal corridor during smiling. The Angle Orthodontist, 76(2), 198-203.

22. Tjan, A. H., Miller, G. D., \& The, J. G. (1984). Some esthetic factors in a smile. The Journal of prosthetic dentistry, 51(1), 24-28.

23. Grosofsky, A., Adkins, S., Bastholm, R., Meyer, L., Krueger, L., Meyer, J., \& Torma, P. (2003). Tooth color: effects on judgments of attractiveness and age. Perceptual and motor skills, 96(1), 43-48.

24. Beall, A. E. (2007). Can a new smile make you look more intelligent and successful?. Dental Clinics of North America, 51(2), 289-297.

25. Tung, A. W., \& Kiyak, H. A. (1998). Psychological influences on the timing of orthodontic treatment. American Journal of Orthodontics and Dentofacial Orthopedics, 113(1), 29-39.

26. Smile, Makeover. (2018). what are the Treatments \& What Does it Cost? [Internet]. You're Dentistry Guide. [cited 2018 May 9]. Available from: https://www.yourdentistryguide.com/smile makeover/

27. Snow, S.R. (1999). Esthetic smile analysis of maxillary anterior tooth width: the golden percentage. Journal of Esthetic and Restorative Dentistry, $1 ; 11(4): 177-84$. 